\title{
Echocardiographic Evaluation of Right Cardiac Function in Patients with Chronic Pulmonary Diseases
}

\author{
Yoshiyuki MiYaharA, ${ }^{1}$ MD, Satoshi IKedA, ${ }^{1}$ MD, Takayuki YoshinAGA, ${ }^{2}$ MD, \\ Kenji YAMAGUCHI, ${ }^{3} \mathrm{MD}$, Eri NishIMURA-SHIRONO, ${ }^{1} \mathrm{MD}$, \\ Toshihiko YAMASA, ${ }^{4} \mathrm{MD}$, Sadanori HAMABE, ${ }^{1} \mathrm{MD}$, \\ Kiyotaka NAKAMURA, ${ }^{1} \mathrm{MD}$, and Shigeru KOHNO, ${ }^{1} \mathrm{MD}$
}

\begin{abstract}
SUMMARY
It is clinically important to evaluate the severity of right ventricular (RV) overload in patients with chronic pulmonary diseases (CPD). For such evaluation, echocardiography has been widely used because the procedure is noninvasive and can be performed repeatedly. We evaluated the severity of RV overload in CPD patients to assess the usefulness of pulsed Doppler echocardiography. The A/E ratio and deceleration time of early RV inflow velocity correlated significantly with the mean pulmonary artery pressure (MPAP) both in patients with and without CPD. The acceleration time/RV ejection time (AcT/ RVET) was significantly lower in CPD patients than control subjects and correlated significantly with MPAP. Furthermore, AcT/RVET improved in patients with mild respiratory failure after oxygen therapy, along with a decrease in MPAP. We also compared the new index of myocardial performance (NI) in control subjects and patients with pulmonary tuberculosis sequelae (TB) undergoing home oxygen therapy. The NI was significantly higher in the TB group. Although these results were satisfactory, the pulsed Doppler echocardiography has certain disadvantages because monitoring is influenced by anatomical factors and it is difficult to perform in patients with atrial fibrillation or tachycardia. We conclude that echocardiography using a Doppler method is a useful noninvasive technique for assessment of the right heart system. The precision of this procedure can be improved by combination with other echocardiographic indices of RV overload. (Jpn Heart J 2001; 42: 483-493)
\end{abstract}

Key words: Pulsed Doppler echocardiography, Peak atrial filling velocity/peak early diastolic filling velocity (A/E), Acceleration time/ejection time (AcT/ET), New index of myocardial performance, Chronic pulmonary disease

PREVIOUS studies have demonstrated that the severity of right ventricular (RV) overload is an important prognostic factor in patients with chronic pulmonary dis-

From ${ }^{1}$ the Second Department of Internal Medicine, Nagasaki University, School of Medicine, ${ }^{2}$ Nagasaki Memorial Hospital, ${ }^{3}$ Omura Municipal Hospital, ${ }^{4}$ Sasebo City General Hospital, Sasebo, Nagasaki, Japan.

Address for correspondence: Yoshiyuki Miyahara, MD, Second Department of Internal Medicine, Nagasaki University School of Medicine, 1-7-1, Sakamoto, Nagasaki, 852-8501, Japan.

Received for publication January 19, 2001.

Revised and accepted March 19, 2001. 
eases (CPD). Therefore, it is important to evaluate the right heart system in these patients as part of the overall clinical assessment. However, the right heart system is a hypobaric system and is markedly influenced by ventilation, posture, and systemic water balance. Therefore, the results of examination of the right heart system should be evaluated more carefully taking into consideration the function of the left heart system. In addition, because the right heart system is closely associated with the status of respiratory function and pulmonary tissue, the system should be assessed in combination with examination of the respiratory system.

Right cardiac function was mainly assessed in the past by invasive techniques involving cardiac catheterization. However, echocardiography is currently one of the most useful procedures for such evaluation because it allows the simple, noninvasive, and reproducible measurement of cardiac function at the bedside. In recent years, the function of the right heart system has been evaluated echocardiographically through changes in RV morphology, ${ }^{1-10)}$ and the use of the Doppler method. ${ }^{11-19)}$ The findings were then compared with the results obtained by invasive procedures, and a satisfactory correlation was obtained between the two data sets. These early studies confirmed that echocardiography is useful for accurate evaluation of right cardiac function.

We have evaluated the severity of right cardiac overload in patients with CPD mainly using pulsed Doppler echocardiography. In this paper, we review the clinical usefulness of the following three indices obtained from RV inflow and ejection flow velocity patterns in our patients: A/E ratio, acceleration time (AcT)/ RV ejection time (RVET), and the new index of myocardial performance (NI) proposed by Tei, et al. ${ }^{20)}$

Measurements of A/E, AcT/RVET and NI: Using the resting end-expiratory parasternal short axis view of the pulmonary valve level or apical four-chamber views, the sample volume was set at the center of the valvular annuli in the RV outflow and inflow tracts parallel to blood flow (Figure 1, left). ${ }^{21,22)}$ The pulsed Doppler waveforms were continuously recorded at a paper speed of 50 or 100 $\mathrm{mm} / \mathrm{sec}$ using a strip chart recorder. The average of 3 to 5 consecutive heart beats was determined.

Figure 1 shows the procedure used to measure the respective parameters. The A/E ratio was calculated by dividing the peak atrial systolic flow velocity (A) by the peak early diastolic filling velocity (E) obtained at the RV inflow tract. ${ }^{23)}$ The AcT/RVET was calculated by dividing the time from the beginning to the peak of RV ejection flow velocity (acceleration time: AcT) by the time from the beginning to the end of RV ejection flow velocity (RV ejection time: RVET). ${ }^{13)}$ Moreover, the deceleration time (DcT) was established as the time from the peak to the end of RV ejection flow velocity. The NI was calculated by dividing the sum of isovolumetric contraction time (ICT) and isovolumetric relaxation time 


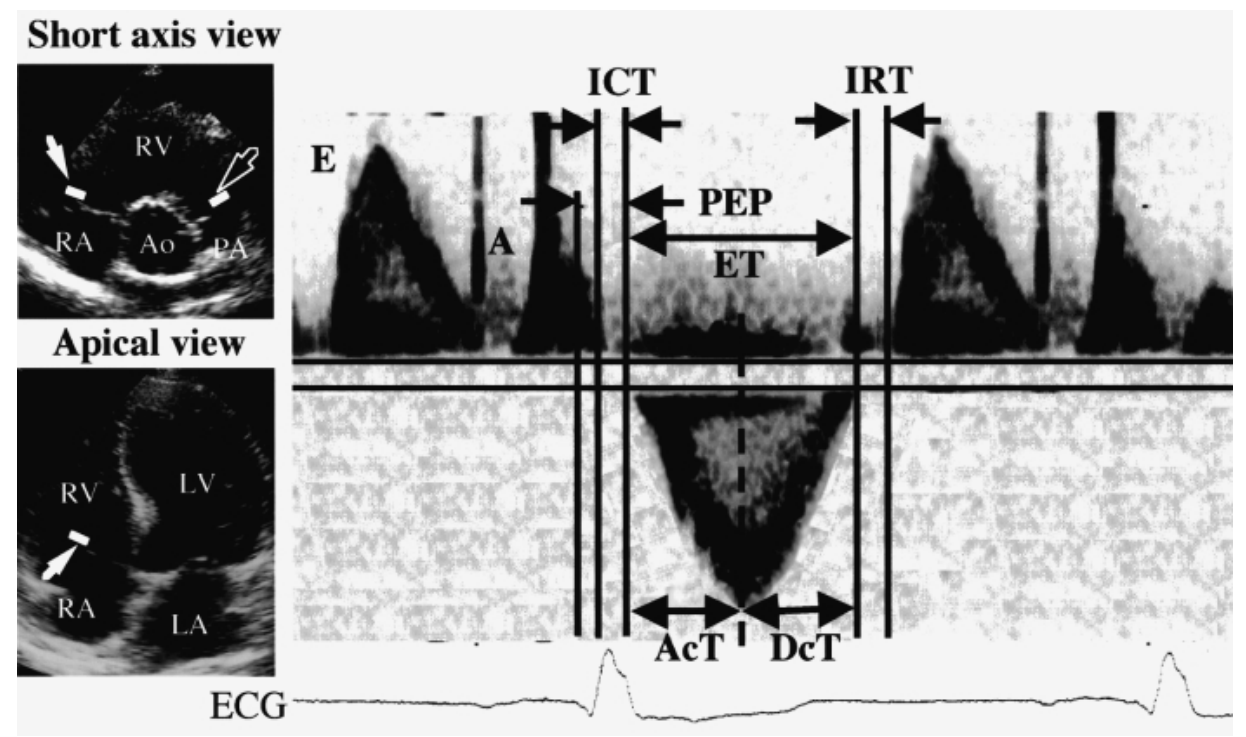

Figure 1. Doppler waveform obtained in the RV inflow (top of right) and ejection flow (bottom of right). In B-mode echocardiogram (left), closed arrow indicates the location of sample volume in the RV inflow and open arrow indicates that in the RV ejection flow.

E: peak early diastolic filling velocity; A: peak atrial systolic flow velocity; PEP=pre-ejection period; ICT=isovolumetric contraction time, IRT=isovolumetric relaxation time; ET=ejection time; AcT=acceleration time; DcT=deceleration time; $\mathrm{ECG}=$ electrocardiogram; $\mathrm{RV}=$ right ventricle; $\mathrm{RA}=$ right atrium; $\mathrm{PA}=$ pulmonary artery; $\mathrm{LV}=$ left ventricle; $\mathrm{LA}=$ left atrium; $\mathrm{Ao}=$ aorta.

(IRT) by RVET. ${ }^{20)}$ The sum of ICT and IRT was calculated by subtracting the interval between the cessation and the onset of RV inflow waveforms from RV ejection time. Correlations among the above A/E ratio, AcT/RVET, NI, and data measured using a Swan-Ganz catheter were compared between the control and CPD groups.

A/E ratio: Although the $\mathrm{A} / \mathrm{E}$ ratio has been frequently evaluated in the left heart system, only a few studies have assessed $\mathrm{A} / \mathrm{E}$ in the right heart system. ${ }^{11,12)}$ To evaluate the significance of $\mathrm{A} / \mathrm{E}$ in patients with mild respiratory failure, we assessed the $\mathrm{A} / \mathrm{E}$ ratio and DcT in 12 control subjects, 25 chronic obstructive pulmonary disease (COPD) patients, and 6 chronic pulmonary thromboembolism (CPTE) patients (Table I). ${ }^{23)}$ Both A/E and DcT correlated positively and significantly with the mean pulmonary arterial pressure (MPAP) in all subjects regardless of the presence or absence of CPD (Figure. 2). ${ }^{23)}$ However, previous studies have reported that the $\mathrm{A} / \mathrm{E}$ ratio is influenced by several factors, such as age, respiration, ${ }^{24-26)} \mathrm{P}-\mathrm{Q}$ interval, stenosis of the atrioventricular valves, atrial fibrillation (Af), and tachycardia above 100 beats/min (due to unimodal waveforms). ${ }^{27}$ In addition, because the $\mathrm{A} / \mathrm{E}$ ratio also depends on atrial pressure, pseudonormalization may occur. ${ }^{28)}$ Therefore, the $\mathrm{A} / \mathrm{E}$ ratio in the right heart system should be 
Table I. Characteristics of Normal Control, CPD and CPTE Groups

\begin{tabular}{lccccccc}
\hline & $n$ & male & $\begin{array}{c}\text { Age } \\
\text { (years })\end{array}$ & $\begin{array}{c}\% \mathrm{FEV} 1 \\
(\%)\end{array}$ & $\begin{array}{c}\% \mathrm{VC} \\
(\%)\end{array}$ & $\begin{array}{c}\mathrm{PaO}_{2} \\
(\mathrm{mmHg})\end{array}$ & $\begin{array}{c}\mathrm{MPAP} \\
(\mathrm{mmHg})\end{array}$ \\
\hline Control & 12 & 7 & $55 \pm 13$ & $83 \pm 8.6$ & $106 \pm 12.1$ & $86 \pm 7$ & $13 \pm 2(n: 10)$ \\
CPD & 25 & 18 & $66 \pm 5$ & $66 \pm 15.7$ & $82 \pm 24.5$ & $75 \pm 13.6$ & $17 \pm 6(n: 21)$ \\
CPTE & 6 & 0 & $61 \pm 6$ & $72 \pm 12.7$ & $88 \pm 19.5$ & $74 \pm 16$ & $17 \pm 5(n: 5)$ \\
\hline
\end{tabular}

Data are mean $\mathrm{SD}, \mathrm{FEV}=$ forced expiratory volume; $\mathrm{VC}=$ vital capacity; $\mathrm{MPAP}=$ mean pulmonary arterial pressure; $\mathrm{PaO}_{2}=$ partial arterial oxygen pressure; $\mathrm{CPD}=$ chronic pulmonary diseases; $\mathrm{CPTE}=$ chronic pulmonary thrombo-embolism
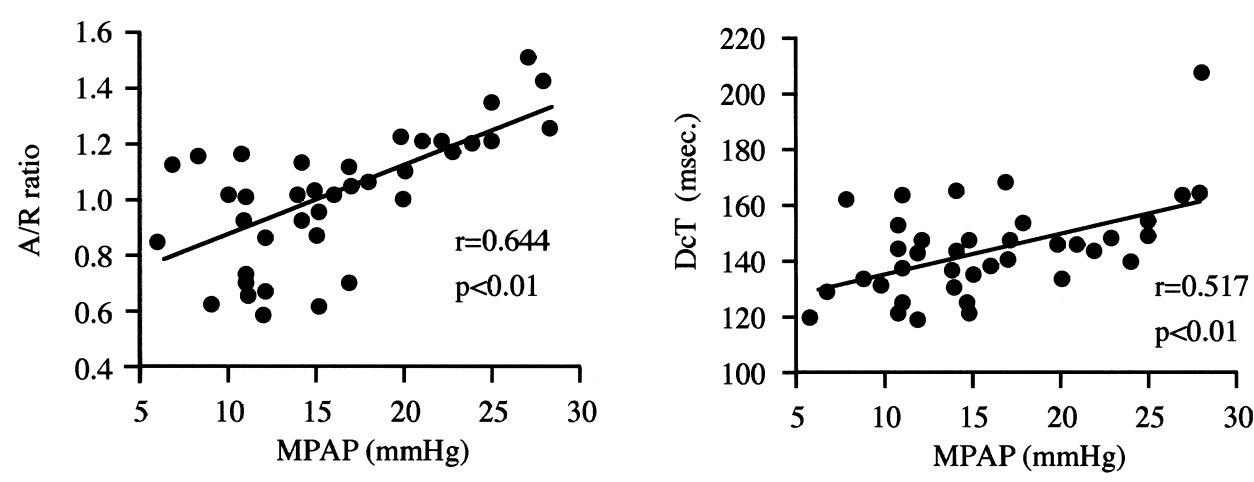

Figure 2. Correlation between MPAP and $\mathrm{A} / \mathrm{E}$ ratio, and $\mathrm{DcT}$. MPAP $=$ mean pulmonary arterial pressure.

evaluated simultaneously with the assessment of DcT along with the measurement of flow velocity patterns in the inferior vena cava and hepatic vein in particular, similar to the measurement of pulmonary venous flow velocity patterns during assessment of the $\mathrm{A} / \mathrm{E}$ ratio in the left heart system. ${ }^{29)}$ Evaluation of the $\mathrm{A} /$ $\mathrm{E}$ ratio means assessment of diastolic function. Diastolic function can also be evaluated by pressure waveforms using negative dp/dt or Tau. Further studies are necessary to compare the $\mathrm{A} / \mathrm{E}$ ratio in the right heart system with these indices.

AcT/RVET: Previous studies from our laboratory compared AcT/RVET between control and CPD patients. ${ }^{30)}$ The results demonstrated that AcT/RVET was significantly lower in CPD patients (Table II), and that AcT/RVET correlated significantly with MPAP (Figure. 3). ${ }^{30)}$ We also examined the effect of oxygen inhalation on this index in patients with mild respiratory failure. For this purpose, we divided patients into three groups based on the level of MPAP (Table III). AcT/RVET correlated significantly with MPAP, and improved following a decrease in MPAP after administration of oxygen (Figure. 4). ${ }^{31)}$ Several studies have previously demonstrated a correlation between AcT/RVET and MPAP, 
Table II. Characteristics of Normal Control and CPD Groups

\begin{tabular}{lrrrrrrr}
\hline & $n$ & male & $\begin{array}{c}\text { Age } \\
(\text { years })\end{array}$ & $\begin{array}{c}\% F E V 1 \\
(\%)\end{array}$ & $\begin{array}{c}\% \mathrm{~V} \\
(\%)\end{array}$ & $\begin{array}{c}\mathrm{PaO}_{2} \\
(\mathrm{mmHg})\end{array}$ & $\begin{array}{c}\mathrm{MPAP}^{(\mathrm{mmHg})} \\
(\mathrm{mmH})\end{array}$ \\
\hline Control & 15 & 9 & $56 \pm 11$ & $75 \pm 12.5$ & $107 \pm 18.6$ & $84 \pm 12.5$ & $11 \pm 3$ \\
CPD & 32 & 19 & $56 \pm 15$ & $59 \pm 18.6$ & $71 \pm 21.6$ & $74 \pm 15.4$ & $18 \pm 68$ \\
\hline
\end{tabular}

Data are mean $\pm \mathrm{SD}$, Abbreviations as in Table I.
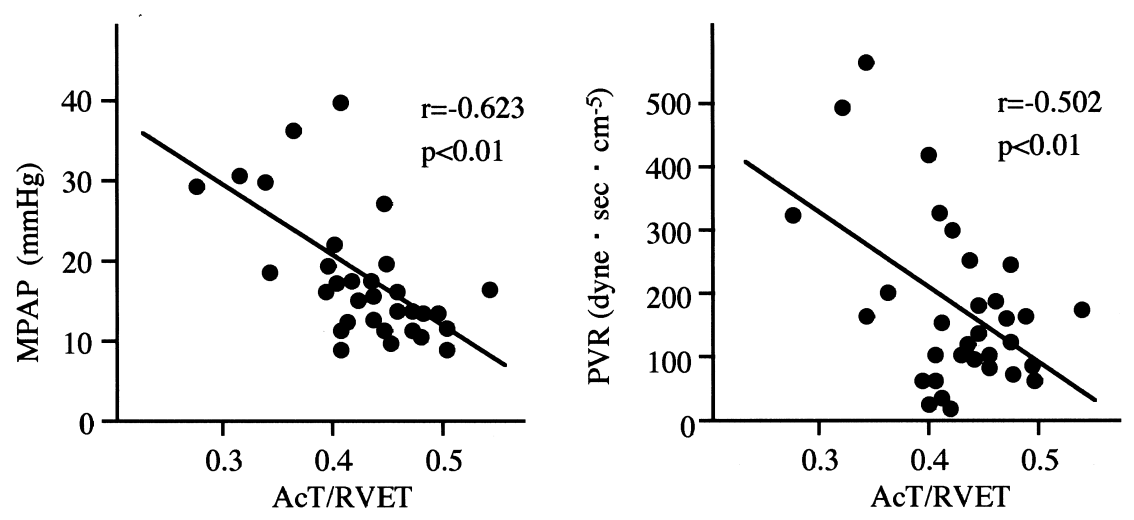

Figure 3. Correlation between AcT/RVET and MPAP, and PVR. PVR=pulmonary vascular resistance.

Table III. Characteristics of CPTE, COPD and PF Groups

\begin{tabular}{lrrcccccr}
\hline$n$ & male & $\begin{array}{c}\% \mathrm{FEV} 1 \\
(\%)\end{array}$ & $\begin{array}{c}\% \mathrm{VC} \\
(\%)\end{array}$ & $\begin{array}{c}\mathrm{PaO}_{2} \\
(\mathrm{mmHg})\end{array}$ & \multicolumn{3}{c}{$\begin{array}{c}\text { MPAP } \\
(\mathrm{mmHg})\end{array}$} & \\
& & & & & & 519 & $20-24$ & $\geqq 25$ \\
\hline CPTE & 12 & 6 & - & - & $77 \pm 21.0$ & 4 & 3 & 5 \\
COPD & 12 & 16 & $46 \pm 15.9$ & $76 \pm 10.7$ & $66 \pm 10.8$ & 5 & 6 & 1 \\
PF & 9 & 7 & $89 \pm 6.6$ & $65 \pm 15.8$ & $76 \pm 25.1$ & 7 & 1 & 1 \\
\hline
\end{tabular}

Data are mean $\pm \mathrm{SD}$, Abbreviations as in Table I, $\mathrm{COPD}=$ chronic obstructive pulmonary disease; $\mathrm{PF}=$ pulmonary fibrosis. 

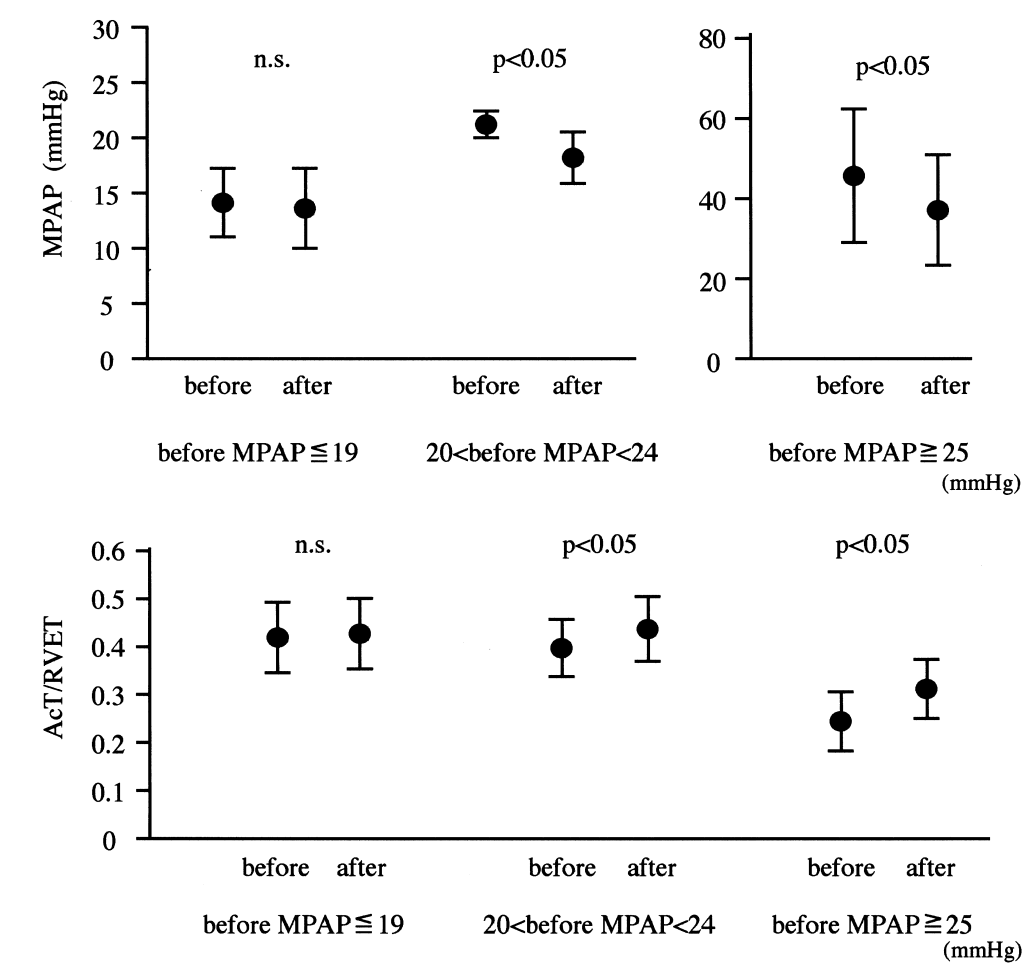

Figure 4. Changes in MPAP and AcT / RVET before and after inhalation of oxygen. Data are mean \pm SD.

therefore, AcT/RVET has been regarded as an index of pressure overload. ${ }^{13-17)}$ Although there is no consensus regarding changes in AcT/RVET after administration of oxygen, ${ }^{32-35)}$ our patients with mild pulmonary hypertension demonstrated that AcT/RVET could be used as an index of improvement of RV overload after oxygen therapy. Furthermore, it was suggested that the course of pressure overload might be followed by monitoring AcT/RVET.

Although AcT/RVET is a very useful index for clinical assessment of pressure overload, the index has certain disadvantages. First, AcT/RVET may be influenced by anatomical changes such as alterations in the pulmonary arterial diameter or valves. Second, the pumping function of the heart, i.e., the RV ejection fraction, may also influence RV outflow velocity patterns. Third, most previous studies examined patients with CPD in a chronic stable state, not an acute exacerbation state. At this stage, it is not clear whether patients during acute exacerbation of CPD follow a similar course, because the MPAP is limited to below $40 \mathrm{mmHg}$ during acute pressure overload.Therefore, further studies should eval- 
uate the correlation between AcT/RVET and MPAP. To date, although all previous studies showed close correlations between AcT/RVET and MPAP, the severity or stage of CPD should also be considered during such evaluations.

NI: Tei, et $\mathrm{al}^{36}$ ) reported that $\mathrm{NI}$ is associated with the prognosis and subjective symptoms of dilated cardiomyopathy or cardiac amyloidosis defined by the NYHA. They also showed that the NI is a novel index for evaluating the prognosis of patients with heart failure. ${ }^{20,36)}$ Indeed, both the ICT and IRT, indices of systolic and diastolic functions, respectively, are prolonged in heart failure, together with the shortening of the ejection fraction. Therefore, it may be reasonable to use the NI during evaluation of heart failure because this index may reflect comprehensive cardiac functions, including systolic and diastolic functions. Regarding both the right and left heart systems, a number of studies have recently reported positive correlations between NI and the prognosis of patients with primary pulmonary hypertension (PPH) ${ }^{37,38)}$ Therefore, NI seems to be suitable for evaluation of the right heart system.

We compared the NI between pulmonary tuberculosis sequelae (TB) patients undergoing HOT and control subjects (Table IV), and demonstrated that there was no overlap in the NI values between the two groups. The NI values

Table IV. Characteristics of Normal Control and TB Groups

\begin{tabular}{lcccccc}
\hline & $n$ & male & $\begin{array}{c}\text { Age } \\
\text { (years) }\end{array}$ & $\begin{array}{c}\text { \%FEV1 } \\
(\%)\end{array}$ & $\begin{array}{c}\% \mathrm{VC} \\
(\%)\end{array}$ & $\begin{array}{c}\mathrm{PaO}_{2} \\
(\mathrm{mmHg})\end{array}$ \\
\hline Control & 37 & 18 & $67 \pm 8$ & - & - & - \\
TB & 29 & 18 & $68 \pm 5$ & $57 \pm 15$ & $43 \pm 10$ & $75 \pm 13$ \\
\hline
\end{tabular}

Data are mean $\pm \mathrm{SD}$, Abbreviations as in Table I, TB: old pulmonary tuberculosis.
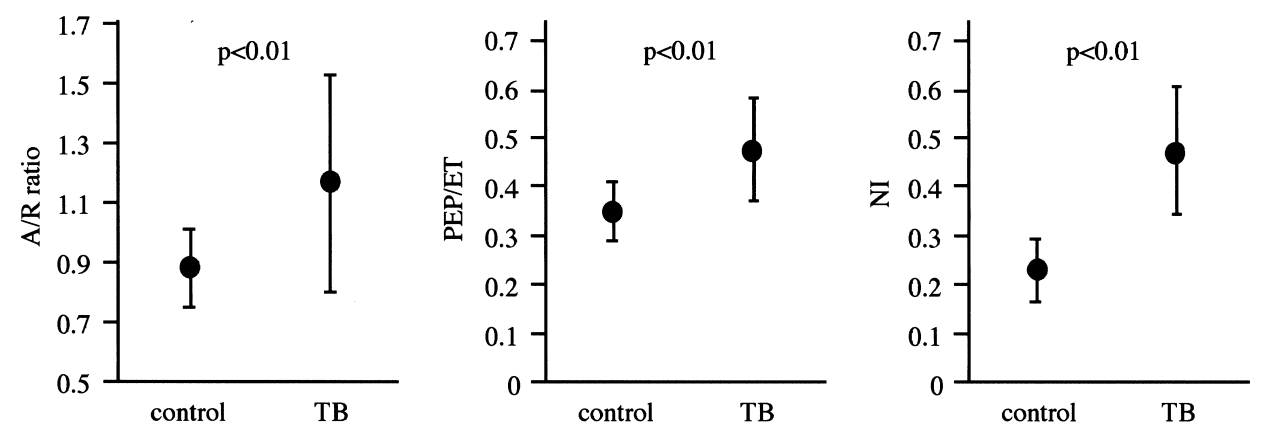

Figure 5. Comparison of A/R ratio, PEP/ET and NI between control and TB. TB: patients with pulmonary tuberculosis sequelae, NI: new index of myocardial performance. Data are mean \pm SD. 
were apparently higher in the TB group than in the control group (Figure 5). ${ }^{39)}$ However, pulmonary arterial pressure (PAP) estimates based on the tricuspid valve regurgitation pressure gradient (TRPG) did not correlate with NI in the TB group. These results suggest that NI might facilitate evaluation of right cardiac functions regardless of blood oxygen and PAP levels, because the NI values were higher even in patients in whom PAP was slightly decreased by HOT than in healthy subjects. Moreover, the results also suggested that NI might facilitate the detection of RV overload before the occurrence of anatomical changes such as RV hypertrophy or dilatation. ${ }^{40)}$ Other than PAP, NI may be associated with the moderate-to-long-term prognosis of CPD patients. Therefore, NI should be further evaluated in the future. However, in CPD patients complicated by diseases that could cause electrocardiographic abnormalities such as Af and bundle branch block or diseases that could affect cardiac functions such as ischemic heart diseases, cardiomyopathy, and valvular heart diseases, should be evaluated carefully. Moreover, although attempts have been reported to clarify the mechanism of changes in NI in comparison with $\mathrm{dp} / \mathrm{dt}$, the details remain unclear. ${ }^{41}$ )

The echocardiographic evaluation of right cardiac functions is roughly classified into morphological procedures and the Doppler method. The following issues have been evaluated morphologically by several investigators: changes in the RV diameter, ${ }^{1,2)} \mathrm{RV}$ contractility, ${ }^{3,4)}$ the severity of RV hypertrophy caused by pressure overload, ${ }^{5)}$ fluttening of the ventricular septum, ${ }^{6}$ early diastolic dip depicted by the M-mode method during movement of the ventricular septum, ${ }^{7}$ and mid systolic closure of the pulmonary arterial valve and disappearance of a dip depicted by the M-mode method. ${ }^{89}$ In addition, right atrial pressure has been evaluated based on the diameter of the inferior vena cava. ${ }^{10)}$ In a clinical setting, however, echocardiographic evaluation of the right heart system is more difficult than that of the left heart system because the thinner RV wall makes echocardiographic visualization of the right heart system more difficult compared to visualization of the left heart system. Therefore, precise volumetric measurement or Mmode echocardiography is more difficult in the right heart system than in the left heart system.

Using Doppler echocardiography, the following issues can be evaluated: A/ $\mathrm{E}$ and DcT mainly as indices of diastolic functions (in association with the left heart system), ${ }^{42-44)}$ AcT/RVET, ${ }^{13-17)}$ PEP/RVET, and TRPG ${ }^{18,19)}$ as indices of systolic function and PAP; and the NI proposed by Tei, et $a l^{20,36)}$ as a comprehensive index. In particular, it was reported that TRPG could be detected in $60 \%$ of healthy subjects and $90 \%$ of patients with pulmonary hypertension $(\mathrm{PH})$. Therefore, it is considered that systolic PAP can be obtained by adding the TRPG value to right atrial pressure (RAP), if there is no stenosis in the RV outflow tract. RAP is frequently used clinically because it can be easily estimated based on the diam- 
eter of the IVC obtained by two-dimensional echocardiography. ${ }^{45)}$ It was recently reported that Tau could be obtained by TR waveforms. ${ }^{46}$

Doppler echocardiography can be performed repeatedly and noninvasively at the bedside. Once the range and location of a sample volume are established, blood flow velocity can be assessed reproducibly by the pulsed Doppler method. The pulsed Doppler echocardiography also allows the continuous and objective recording of changes in blood flow. However, the pulsed Doppler method has some disadvantages, including the following: differences in technical skills may cause errors; the measurement is influenced by respiration or posture; and the Doppler method is not indicated for patients undergoing mechanical ventilation. In the future, it is important to apply novel techniques such as tissue Doppler imaging, which is already used to evaluate the left heart system. Moreover, the accuracy of the evaluation should be increased in combination with other echocardiographic indices, and using various types of stress such as drugs and exercise.

In conclusion, we have evaluated the severity of RV overload in patients with CPD using pulsed Doppler echocardiography. It has been suggested that the right cardiac functions of CPD can be predicted noninvasively using pulsed Doppler echocardiography in combination with the assessment of RV ejection flow or inflow velocity patterns, and the reactivity of the respective indices after oxygen therapy.

\section{REFERENCES}

1. Starling MR, Crawford MH, Sorensen SG, O'Rourke RA. A new two-dimensional echocardiographic technique for evaluating right ventricular size and performance in patients with obstructive lung disease. Circulation 1982; 66: 612-20.

2. Foale R, Nihoyannopoulos P, McKenna W, et al. Echocardiographic measurement of normal adult right ventricle. Br Heart J 1986; 56: 33-44.

3. Kaul S, Tei C, Hopkins JM, Shah PM. Assessment of right ventricular function using two-dimensional echocardiography. Am Heart J 1984; 107: 526-31.

4. Hammarstrom E, Wranne B, Pinto FJ, Puryear J, Popp RL. Tricuspid annular motion. J Am Soc Echocardiogr 1991; 4: 131-9.

5. Baker BJ, Scovil JA, Kane JJ, Murphy ML. Echocardiographic detection of right ventricular hypertrophy. Am Heart J 1983; 105: 611-4.

6. Portman MA, Bhat AM, Cohen MH, Jacobstein MD. Left ventricular systolic circular index; an echocardiographic measure of transseptal pressure ratio. Am Heart J 1987; 114: 1178-82.

7. Thompson CR, Kingma I, MacDonald RF, Blelnkie I, Tyberg JV, Smith ER. Transseptal pressure gradient and diastolic ventricular septal motion in patients with mitral stenosis. Circulation 1987; 76: 974-80.

8. Weyman AE, Dillon JC, Feigenbaum H, Chang S. Echocardiographic patterns of pulmonary valve motion with pulmonary hypertension. Circulation 1974; 50: 905-10.

9. Tahara M, Tanaka H, Nakao S, et al. Hemodynamic determinants of pulmonary valve motion during systole in experimental pulmonary hypertension. Circulation 1981; 64: 1249-55. 
10. Gullace G, Savoia MT. Echocardiographic assessment of the inferior vena cava wall motion for studies of right heart dynamics and function. Clin Cardiol 1984; 7: 393-404.

11. Marangoni S, Scalvini S, Schena M, Vitacca M, Quadri A, Levi G. Right ventricular diastolic function in chronic obstructive lung disease. Eur Respir J 1992; 5: 438-43.

12. Yu CM, Sanderson JE, Chan S, Yeung L, Hung YT, Woo KS. Right ventricular diastolic dysfunction in heart failure. Circulation 1996; 93: 1509-14.

13. Kitabatake A, Inoue M, Asao M, et al. Noninvasive evaluation of pulmonary hypertension by a pulsed Doppler technique. Circulation 1983; 68: 302-9.

14. Kosturakis D, Golsberg SJ, Allen HD, Loeber C. Doppler echocardiographic prediction of pulmonary arterial hypertension in congenital heart disease. Am J Cardiol 1984; 53: 1110-5.

15. Davestani A, Mahan G, Cardin JM, et al. Evaluation of pulmonary artery pressure and resistance by pulsed Doppler echocardiography. Am J Cardiol 1987; 59: 662-8.

16. Martin-Duran R, Larman M, Trugeda A, et al. Comparison of Doppler-determined elevated pulmonary arterial pressure with pressure measured at cardiac catheterization. Am J Cardiol 1986; 57: 859-63.

17. Isobe M, Yazaki Y, Takaku F, et al. Prediction of pulmonary arterial pressure in adults by pulsed Doppler echocardiography. Am J Cardiol 1986; 57: 316-21.

18. Nazeyrollas P, Metz D, Chapoutot L, et al. Diagnostic accuracy of echocardiography-Doppler in acute pulmonary embolism. Int J Cardiol 1994; 47: 273-80.

19. Kasper W, Geibel A, Tiede N, et al. Distinguishing between acute and subacute massive pulmonary embolism by conventional and Doppler echo-cardiography. Br Heart J 1993; 70: 352-6.

20. Tei C, Ling LH, Hodge DO, et al. New index of combined systolic and diastolic myocardial performance: a simple and reproducible measure of cardiac function-a study in normals and dilated cardiomyopathy. J Cardiol 1995; 26: 357-66.

21. Okamoto M, Miyatake K, Kinoshita N, Sakakibara H, Nimura Y. Analysis of blood flow in pulmonary hypertension with the pulsed Doppler flowmeter combined with cross sectional echocardiography. Br Heart J 1984; 51: 407-15.

22. Lighty GW Jr, Gargiulo A, Kronzon I, Politzer F. Comparison of multiple views for the evaluation of pulmonary arterial blood flow by Doppler echo cardiography. Circulation 1986; 74: 1002-6.

23. Nakamura K, Miyahara Y, Ikeda S, Naito T. Assessment of right ventricular diastolic function by pulsed Doppler echocardiography in chronic pulmonary disease and pulmonary thromboembolism. Respiration 1995; 62: 237-43.

24. Gardin JM, Dabestani A, Takenaka K, et al. Effect of imaging view and sample volume location on evaluation of mitral flow velocity by pulsed Doppler echocardiography. Am J Cardiol 1986; 57: 1335-9.

25. Voutilainen S, Kupari M, Hippenlainen M, Karppinen K, Ventila M, Heikkila J. Factors influencing Doppler indexes of left ventricular filling in healthy persons. Am J Cardiol 1991; 68: 653-9.

26. Maurice PP, Pringle SD, Cobbe SM. Reference values and reproducibility of Doppler echocardiography in the assessment of the tricuspid valve and right ventricular diastolic function in normal subjects. Am J Cardiol 1991; 67: 269-73.

27. Voutilainen S, Kupari M, Hipplainen M, Karppinen K, Ventila M, Heikkila J. Factors influencing Doppler indexes of left ventricular filling in healthy persons. Am J Cardiol 1991; 68: 653-9.

28. Nishimura RA, Abel MD, Hatle LK, Tajik AJ. Assessment of diastolic function of the heart: background and current applications of Doppler cardiography. PART II, clinical studies. Mayo Clin Proc 1989; 64: 181-204.

29. Klein AL, Hatle LK, Burstow DJ, et al. Comprehensive Doppler assessment of right ventricular function in cardiac amyloidosis. J Am Coll Cardiol 1990; 15: 99-108.

30. Yamasa T, Imamura T, Nakashima T, Kurobe K. Assessment of pulmonary artery pressure by pulsed Doppler echocardiography in patients with chronic pulmonary diseases. Jpn Circ J 1993; 57: 70-6.

31. Hamabe S, Miyahara Y, Ohta M, Naito T, Ikeda S. Pulsed Doppler echocardiographic assessment of changes in pulmonary artery pressure during oxygen breathing. Respiration 1996; 63: 35-41.

32. Ashtoch K, Mead G, Dunsky M. Early effect of oxygen administration and prognosis in chronic obstructive pulmonary disease and cor pulmonale. Am Rev Respir Dis 1983; 127: 399-404.

33. Beard JT 2nd, Newman JH, Loyd JE, Byrd BF 3rd. Doppler estimation of changes in pulmonary artery pressure during hypoxic breathing. J Am Soc Echocardiogr 1991; 4: 121-30. 
34. Vogel M, Weil J, Stern H, Buhlmeyer K. Responsiveness of raised pulmonary vascular resistance to oxygen assessed by pulsed Doppler echocardiography. Br Heart J 1991; 66: 277-80.

35. Ritter SB, Cooper RS, Golinko RJ. Noninvasive assessment of pulmonary hypertension and pulmonary vascular reactivity in congenital heart desease; pulsed Doppler application. J Cardiovasc Ultrasonics 1986; 5: 213-21.

36. Tei C, Dujardin KS, Hodge DO, Kyle TA, Tajik AJ, Seward JB. Doppler index combining systolic and diastolic myocardial performance: clinical value in cardiac amyloidosis. J Am Coll Cardiol 1996; 28: 658-64.

37. Yeo TC, Dufardin KS, Tei C, Mahoney DW, McGoon MD, Seward JB. Value of a Doppler-derived index combining systolic and diastolic time interval in predicting outcome in primary pulmonary hypertension. Am J Cardiol 1998; 81: 1157-61.

38. Tei C, Dujardin KS, Hodge DO, et al. Doppler echocardiographic index for assessment of global right ventricular function. J Am Soc Echocardiogr 1996; 9: 838-47.

39. Yamaguchi K, Miyahara Y, Yakabe K, et al. Right ventricular impairment in patients with chronic respiratory failure on home oxygen therapy-non-invasive assessment using a new Doppler index. J Int Med Res 1999; 26: 239-47.

40. Nishimura E, Ikeda S, Naito T, et al. Evaluation of right-ventricular function by Doppler echocardiography in patients with chronic respiratory failure. J Int Med Res 1999; 27: 65-73.

41. Tei C, Nishimura RA, Seward JB, Tajik AJ. Noninvasive Doppler-derived myocardial performance index: correlation with simultaneous measurements of cardiac catheterization measurements. J Am Soc Echocardiogr 1997; 10: 169-78.

42. Nishimura RA, Abel MD, Hatle LK, Tajik AJ. Assessment of diastolic function of the heart: background and current applications of Doppler echocardiography. Part II. Clinical studies. Mayo Clin Proc 1989; 64: 71-81.

43. Appleton CP, Hatle LK, Popp RL. Demonstration of restrictive ventricular physiology by Doppler echocardiography. J Am Coll Cardiol 1988; 11: 757-68.

44. Appleton CP, Hatle LK, Popp RL. Relation of transmitral flow velocity patterns to left ventricular diastolic function; new insights from a combined hemodynamic and Doppler echocardiographic study. J Am Coll Cardiol 1988; 12: 426-40.

45. Kircher BJ, Himelman RB, Schiller NB. Noninvasive estimation of right atrial pressure from the inspiratory collapse of the inferior vena cava. Am J Cardiol 1990; 66: 493-6.

46. Nishimura RA, Schwartz RS, Tajik AJ, Holmes DR Jr. Noninvasive measurement of rate of left ventricular relaxation by Doppler echocardiography. Circulation 1993; 88: 146-55. 